\title{
USOS DO ESPAÇO, LIBERDADES E CONSTRANGIMENTOS São Paulo, Cidade Limpa: estudo de caso
}

\author{
Helena Pires \\ Universidade do Minho, Portugal
}

\begin{abstract}
Resumo: As formas sensíveis que se interpõem à experiência quotidiana de circulação pelo espaço urbano encontram na publicidade exterior um dos meios mais propícios ao exercício da vida social. Porém, a publicidade exterior impõe-se numa relação dialógica nem sempre pacífica, entendida como uma ameaça à ordem (desordem) da cidade percebida. Poderá a publicidade deixar de querer afirmar o lugar da persuasão, da sedução e da poética no quadro da vida urbana contemporânea? Em 26 de Setembro de 2006, a Câmara Municipal de São Paulo, no Brasil, aprovou a Lei Cidade Limpa, visando a proibição da publicidade exterior. Desde então, uma acérrima polémica tem ocupado cidadãos, políticos, arquitetos, urbanistas, publicitários, bem como artistas, entre diversos tipos de interlocutores, na defesa de pontos de vista por vezes radicalmente irreconciliáveis. É nossa convicção que subjacente a uma tal discussão se encontram diferentes noções de felicidade, individual ou coletiva, que na sua particular aplicação ao espaço e cultura da cidade, em fase de preparação da Copa do Mundo de 2014 (em São Paulo), importa cartografar.
\end{abstract}

Palavras-chave: usos do espaço urbano; publicidade exterior; felicidade; liberdades e constrangimentos.

\section{Introdução}

Uma visita à cidade de São Paulo, antes de 2007, dificilmente deixaria de impressionar o olhar, pelo impacto visual que a publicidade exterior então originava na paisagem. A par de alguns edifícios ou estruturas de interesse arquitetónico e cultural, impunha-se na paisagem a expressão excessiva de profusas e frequentemente gritantes mensagens comerciais. Parecendo debater-se entre si, numa tentativa de rompimento com uma certa indiferença e apatia geral dos passantes, outdoors, lonas, néons e mesmo letreiros comerciais de grande escala, compostos de letras garrafais, indiciavam já os limites de tolerância ao espaço de visibilidade de uma cidade que ao mesmo tempo se exibia na sua imensidão aparentemente infinita. Sobretudo, São Paulo assumia-se como uma cidade-espetáculo desgarrada de qualquer outra pretensão que não a da celebração do entretenimento e do consumo através da transformação em imagem de uma cultura que se afirma exaltante e, como tal, sedenta da permanente invenção do Novo.

Se, por um lado, a paisagem visual de São Paulo conviria a Guy Debord (1992 [1967]) a título de exemplo ilustrativo do conceito de "sociedade do espetáculo", por outro, prestar-se-ia ainda a uma experiência similar à experiência que Jean Baudrillard 
encetou percorrendo algumas das principais cidades da America (1986) sideral dos anos 80, de que resultou um paradigmático ensaio sobre o caráter hiper-real da modernidade. Sobretudo, tratar-se-ia de um caso que não deixaria de servir de oportuno estímulo a uma reflexão sobre A Euforia Perpétua (Bruckner, 2002), o frenesim do prazer e do consumo, que caracterizam a cultura ocidental contemporânea, cujo valor ético de algum modo acabou por se esgotar com a própria crise da modernidade.

Para surpresa de muitos, em 26 de Setembro de 2006, a Câmara Municipal de São Paulo aprovou a Lei Cidade Limpa ${ }^{8}$, com o propósito de regulamentar o uso do espaço urbano por parte da comunicação visual comercial, ou seja, restringindo a publicidade exterior e anúncios indicativos.

\section{Sobre a noção de felicidade}

Desde logo associada quer ao prazer, quer à virtude, a felicidade poderá ser entendida como um "problema" individual, mas também como um valor fundamental para a vida política e social. Tendo por fim a aplicação do conceito ao estudo de caso que tencionamos discutir, importar-nos-á reportar a esta dupla acepção.

Questionemos antes de mais a natureza da felicidade a partir da noção de prazer. Pode o prazer simplesmente definir-se como um bem, uma virtude a que todos aspiram? Estará o prazer intimamente associado à natureza humana, no sentido em que procuramos evitar a dor e, como tal, tendemos para o prazer?

Seja como for, a atribuição de valor ao prazer não é absolutamente consensual. Para Platão, o prazer em si não é necessariamente um bem, na medida em que aquele não é, em rigor, o contrário do mal que a dor, por exemplo, significaria. Também Aristóteles alerta para a existência de diferentes espécies de prazeres, uns provenientes de ações virtuosas, outros de ações menos nobres. Para este último, o prazer encontra-se, sobretudo, associado à atividade. Diz Aristóteles, “sem atividade não há prazer”. E considerando, com as palavras do filósofo, que a vida é uma espécie de atividade, o prazer poderá ser entendido como uma qualidade universal, se atendermos a que,

\footnotetext{
${ }^{8}$ A Prefeitura de São Paulo, sob o mandato de Gilberto Kassab, então Prefeito do Município de São Paulo, regulamentou, através de um decreto publicado no Diário Oficial da Cidade em 6 de Dezembro de 2006, a lei $\mathrm{n}^{0}$ 14.223, visando eliminar a poluição visual em São Paulo, proibir todo tipo de publicidade externa, como outdoors, painéis em fachadas de prédios, backlights e frontlights e ainda anúncios publicitários em táxis, autocarros e bicicletas. A legislação procurou ainda restringir os anúncios indicativos, isto é, aqueles que identificam no próprio local a actividade exercida. Foi entretanto estipulado um período de adaptação às novas exigências (até 31 de Março de 2007).

${ }^{9}$ Em a Ética Nicomaquea, precisamente, Aristóteles dedica dois dos seus capítulos aos problemas do prazer e da felicidade.
} 
supostamente, "todos desejam viver”. O bem e o mal são próprios não dos prazeres em si, mas das atividades a que correspondem. Assim, é bom o prazer associado a uma atividade boa, e perverso o prazer associado a uma atividade má.

Voltando à noção de felicidade propriamente dita, convoquemos uma vez mais Aristóteles, segundo o qual a felicidade é o "fim de todo o humano", um fim que se procura alcançar por si mesmo e não um meio que visaria a busca de outra coisa fora da felicidade em si mesma. Nesta medida, podemos dizer que a felicidade não é necessariamente coincidente com o prazer. A vida feliz, segundo Aristóteles, é a vida conforme à virtude, a qual tem lugar no esforço e não na diversão. Não será por acaso que o pensador distingue as atividades intelectuais das atividades dos sentidos. São as primeiras aquelas às quais se poderá associar, verdadeiramente, a virtude da felicidade ou, melhor dito, da felicidade perfeita. Ao conhecimento e à sabedoria associam-se as atividades e os prazeres mais virtuosos. É interessante notar que para Aristóteles a atividade perfeita é a actividade contemplativa. Na verdade, defende o filósofo que "a felicidade radica no ócio, já que trabalhamos para obter o ócio e fazemos a guerra para obter a paz”. A felicidade será, assim, uma espécie de contemplação.

Em a Carta sobre a Felicidade, Epicuro, fundador, a par de Zenão de Cício, de uma das duas principais correntes filosóficas helenísticas (o epicurismo e o estoicismo), afastase radicalmente de Aristóteles, ao afirmar o individualismo em resposta à crise da polis, do social e das cidades-estado. Aconselhando a recusa da vida pública, Epicuro defendia que o objecto essencial da filosofia consistia em conduzir-nos à felicidade pelo caminho mais curto. Não podendo encontrar-se fora de nós mesmos, a felicidade, para o filósofo, corresponderia a "uma qualidade da existência, alcançável em vida e que se não for obtida neste mundo estará para sempre perdida”. Evitar o sofrimento e a inquietação, tendo em vista "alcançar o estádio em que não se sofre no corpo e não se está perturbado na alma” traduz, segundo Epicuro, a fórmula possível da felicidade. Diz Epicuro a Meneceu, seu destinatário privilegiado: “Acostuma-te nesta questão a pensar que para nós a morte nada é, pois todo o bem e todo o mal residem na sensação".

Já Séneca, embora admitindo concordância com alguns dos aspetos da filosofia de Epicuro, formula, em Da Vida feliz, em moldes diferentes o seu entendimento da felicidade. Em primeiro lugar, não deixando de partilhar do ponto de vista da afirmação do individualismo, Séneca vê na "multidão" e no espírito de "imitação" que lhe é próprio um obstáculo à procura do verdadeiro caminho ou via para a felicidade. Diz o filósofo, "a opinião da multidão é indício do pior. Procuremos, pois, aquilo que é o melhor e não o que é mais comum, aquilo que nos colocará na posse de uma felicidade eterna e não o que tem a aprovação do vulgar”. Em particular, Séneca preocupa-se em 
separar a verdadeira felicidade, a qual seria "uma beleza interna e oculta" daquilo que se afirma pela simples aparência, isto é, do mero prazer. Ao contrário da felicidade, associada à virtude e à sabedoria, "o prazer conduz a um ponto em que cessa, e desde o início conhece o seu fim”. A verdadeira felicidade, apenas alcançável na condição de uma alma e corpo sãos, consistiria então em "uma vida conforme à sua própria natureza”, o que quererá dizer uma vida conforme à virtude como coisa simultaneamente elevada, sublime e real. Ou, dito ainda de outro modo, a felicidade corresponderá a um estádio de desocultação, ou seja, à descoberta, para lá das aparências, dos objetos próximos pelos quais passamos sem os ver ${ }^{10}$.

A história do pensamento dá conta de diferentes noções de felicidade. Transportandonos já para a Modernidade, constatamos que a felicidade se encontra necessariamente associada à satisfação dos desejos, bem como ao bem-estar material. Em lugar da antiga condenação moral e religiosa do prazer que a Ética Protestante e o Espírito do Capitalismo, de Max Weber, procura esclarecer, impera na sociedade de consumo o direito inalienável à felicidade. De um modo particular, o Maio de 68, sobretudo com Sartre, promove a inversão de valores, na defesa da liberdade interior e do direito ao prazer. Contrariando a ideia de uma felicidade espiritual, ou mesmo a ideia da negação da felicidade associada ao prazer, que o pessimismo agostiniano, nomeadamente, havia defendido, a modernidade propõe uma conceção do ser humano segundo a qual este é um ser de sensação e desejo.

Pascal Bruckner (2002), em A Euforia Perpétua, propõe uma paradoxal definição de felicidade. Diz o autor (Ibidem: 15):

O nosso tempo conta-nos uma estranha fábula: a de uma sociedade dedicada ao hedonismo, para a qual tudo se torna causa de irritação e de suplício. A infelicidade não é só a infelicidade: é, ainda pior, o fracasso da felicidade.

Na verdade, a partir das Luzes e da Revolução Francesa, a promessa de felicidade dirigida a toda a humanidade tornou-se num imperativo ético para a sociedade ocidental. Também Lipovetsky (2007), referindo-se à sociedade do hiperconsumo, fala do caráter paradoxal da felicidade. Nas palavras do autor (Ibidem: 12):

As solicitações hedonistas são omnipresentes. A inquietação, a decepção, a insegurança social e pessoal aumentam. Estes são alguns dos aspectos que fazem da sociedade de hiperconsumo a civilização da felicidade paradoxal.

\footnotetext{
${ }^{10}$ Sobre a noção de "verdadeira felicidade", em Da Vida Feliz, diz Séneca: "Esse bem não está longe, encontrá-lo-emos, basta saber onde estender as mãos; mas agora estamos como no meio das trevas, passando pelos objectos próximos sem os ver...”.
} 
A experiência quotidiana contemporânea, que Maffesoli (1979) caracteriza através da noção de presenteísmo, referindo-se ao primado e ao culto do presente, em detrimento da ideia de um movimento progressista rumo a um futuro prometedor, afeta, de modo particular, a própria noção de felicidade. Associada às possibilidades de realização humanas, a felicidade não deixa de se constituir no quadro de uma descrença generalizada, projetada como uma ficção eternamente desfasada da existência no momento presente. Ao mesmo tempo, a vivência do instante é acrescida de uma intensidade trágica, favorecendo-se assim, precisamente, o sentido da efemeridade, o qual motiva o consumo em geral e legitima, em especial, o papel da publicidade.

\section{Cidade Limpa, um caso}

A discussão pública que o caso São Paulo, Cidade Limpa tem suscitado conta com vivos defensores da regulação, do planeamento e da disciplina (urbanistas, arquitetos e promotores turísticos), por um lado, e, por outro, com publicitários, anunciantes, profissionais ligados aos negócios e artistas, os quais não deixam de tecer duras críticas à Lei, em virtude de as suas próprias práticas terem sido violentamente afetadas em resultado da sua aplicação. Não se confinando à extinção da publicidade exterior (com exceção daquela afeta ao mobiliário urbano, para lá de algumas outras exceções), o projeto Cidade Limpa estendeu a sua ação ao varrimento, inclusivé, em algumas zonas da cidade, de pinturas murais e de graffiti. O eficiente pincel ocre com que se passou a limpar a cidade chegou mesmo a fazer tábua rasa de conhecidas obras de arte pública/urbana de valor estético e cultural reconhecido, como é o caso dos Gêmeos ${ }^{11}$, artistas com notoriedade internacional que viram uma das suas obras, no Centro de São Paulo, literalmente apagada ${ }^{12}$.

No entanto, o projeto São Paulo, Cidade Limpa foi apresentado na qualidade de caso internacional na Exposição Universal de Xangai 2010. A propósito do "exemplo a ser seguido por outras municipalidades”, sintetizou então Marcos Caramuru, Cônsul do Brasil em Xangai, justificando as transformações na paisagem urbana paulistana e referindo-se a: "um país que se moderniza, que tem potencial económico, de negócios e que conquista cada vez mais espaço no cenário internacional”. De facto, o Pavilhão de São Paulo localizava-se, por altura da exposição, na Área de Melhores Práticas Urbanas.

\footnotetext{
11 "Otávio e Gustavo Pandolfo, conhecidos internacionalmente como Os Gêmeos, foram entrevistados na última segunda-feira (14/12), no programa Roda Viva - espaço geralmente reservado a políticos e celebridades -, da TV Cultura. Falando sobre o fato de o grafite ter conquistado espaço como forma de arte e chegar até a museus, Os Gêmeos aproveitaram para cutucar a prefeitura de SP, que apagou mural feito pela dupla, num acesso à avenida 23 de Maio, no Centro". ('Arte - Os Gêmeos criticam Cidade Limpa', $B R$ Press, São Paulo, qui, 17 de dezembro de 2009).

${ }^{12}$ Note-se que São Paulo era até há pouco tempo frequentemente designada a "capital do graffiti”.
} 
Um tal acontecimento denuncia, em primeiro lugar, uma associação implícita e imediata entre publicidade e "poluição visual". A publicidade é de algum modo equiparada a "lixo" que desejavelmente se deverá "limpar" da paisagem. Em segundo lugar, tendo em conta o referido entendimento sobre a publicidade, esta é considerada como um problema social. É em nome do turismo e lazer, mas também invocando "o bem-estar estético, cultural e ambiental da população", que a Lei Cidade Limpa procura legitimar-se, fantasmagorizando sobre o caos e o "visual selvagem", préexistentes.

Ao mesmo tempo, comerciantes, anunciantes, publicitários e outros profissionais da área reagem vivamente aos impactos sociais e económicos negativos resultantes da aplicação da Lei. Já em 2007 era publicado um pequeno livro de crónicas intitulado precisamente São Paulo, Cidade Limpa, da autoria de Gustavo Piqueira, expressivo das dificuldades particulares dos comerciantes, consequentes da regulamentação dos designados "núncios indicativos" (letreiros comerciais). Por meio de um registo semificcional e irónico, o autor procura dar visibilidade a pequenas-grandes tragédias do quotidiano. Sob a forma de uma espécie de denúncia poética, Piqueira expõe o absurdo de algumas situações concretas em resultado, nomeadamente, da aplicação de normas rígidas quanto a limites de escala, de medida e de economia de linguagem que terão comprometido, em alguns casos, a função informativa, fática e outras da mensagem. Inesperadamente, porém, a necessidade de adequação dos recursos de linguagem existentes aos imperativos da Lei terá, por outro lado, estimulado pontualmente a criatividade dos comerciantes...

Prestemos atenção ao art $3^{\circ}$ da referida Lei, através do qual se expõe a principal argumentação que lhe serve de fundamentação retórica:

Art. $3^{\circ}$. Constituem objetivos da ordenação da paisagem do Município de São Paulo o atendimento ao interesse público em consonância com os direitos fundamentais da pessoa humana e as necessidades de conforto ambiental, com a melhoria da qualidade de vida urbana, assegurando, dentre outros, os seguintes:

I - o bem-estar estético, cultural e ambiental da população;

II - a segurança das edificações e da população;

III - a valorização do ambiente natural e construído; 
IV - a segurança, a fluidez e o conforto nos deslocamentos de veículos e pedestres;

V - a percepção e a compreensão dos elementos referenciais da paisagem;

VI - a preservação da memória cultural;

VII - a preservação e a visualização das características peculiares dos logradouros e das fachadas;

VIII - a preservação e a visualização dos elementos naturais tomados em seu conjunto e em suas peculiaridades ambientais nativas;

IX - o fácil acesso e utilização das funções e serviços de interesse coletivo nas vias e logradouros;

$\mathrm{X}$ - o fácil e rápido acesso aos serviços de emergência, tais como bombeiros, ambulâncias e polícia;

XI - o equilíbrio de interesses dos diversos agentes atuantes na cidade para a promoção da melhoria da paisagem do Município”.

Em primeiro lugar, destacamos o facto de a Lei São Paulo, Cidade Limpa se autolegitimar, em termos discursivos, com base na defesa das "necessidades de conforto ambiental", na "melhoria da qualidade de vida urbana", bem como na defesa do "bemestar estético, cultural e ambiental”. À relação com o ambiente urbano são deste modo idealmente associados os valores materiais do prazer e do bem-estar. Repare-se ainda nas expressões usadas logo à cabeça do artigo: “interesse público" e "direitos fundamentais da pessoa humana". Entendendo-se o bem-estar como uma forma possível de traduzir, na Idade Moderna, o prazer e a felicidade, poder-se-á dizer, à maneira de Adam Smith, que a uma tal formulação subjaz a convicção de que existe uma espécie de "direito natural à felicidade”. A “ordenação da paisagem” que a Lei visa promover é em si apresentada como um bem necessário, simultaneamente, ao bemestar e à felicidade individual e coletiva. Invocando Jeremy Bentham, segundo o qual importava promover "a maior felicidade para o maior número", podemos dizer que é de uma noção de felicidade simultaneamente hedonista e utilitarista que aqui se trata de defender. Pautando a sociedade ocidental desde a sua secularização, com as Luzes, a eleição da satisfação dos desejos pessoais, mas também a "promessa de felicidade" para todos constituem as principais linhas de conduta imprescindíveis à justificação da ação política e social. A vida urbana quotidiana compõe, deste ponto de vista, uma esfera 
particular de interseção dos interesses privados e comuns. Na defesa da maior felicidade possível para o maior número possível de pessoas, a Lei ocupa um papel fundamental, pois como diria Bentham, "se cada um deve agir de modo a promover ao máximo a felicidade própria e a de outrem, é necessário que sejam as leis a favorecer isto, dirigindo a actividade da pessoa".

Ainda segundo o art. $3^{\mathrm{o}}$ da Lei, um dos principais objetivos seria a defesa de: "a percepção e a compreensão dos elementos referenciais da paisagem”. Ou seja, a eliminação ou as restrições à publicidade exterior visará a desobstrução dos obstáculos à perceção da realidade referencial da paisagem, realidade essa que a publicidade, supostamente, ocultará. A esta preocupação não será estranho, uma vez mais, o pensamento de Guy Debord. Segundo o autor, na sociedade de consumo, à qual Debord se refere como $A$ Sociedade do Espectáculo, “o mundo sensível é substituído pelas imagens". Inspirando-se na perceção da paisagem da America, também Jean Baudrillard se refere ao fenómeno de desterritorialização, isto é, ao fenómeno de transformação do território em imagem, em parte operado por via da publicidade exterior, o que tornará a experiência de circulação similar à experiência cinematográfica. Numa celebérrima passagem, diz Baudrillard, "não sabemos se é o cinema que se faz à imagem da paisagem norte-americana ou se é a paisagem que se faz à imagem do cinema”.

Continuando com o enunciado em destaque respeitante à Lei São Paulo, Cidade Limpa, note-se que implicitamente se entende a publicidade exterior como uma superfície aparente e enganadora, uma superfície de ocultação dos elementos referenciais da paisagem, isto é, fundamentalmente, da arquitetura e do "ambiente natural”. Arquitetos, urbanistas e promotores do turismo em São Paulo têm-se manifestado tenazes defensores da Lei, invocando, precisamente, a valorização do património edificado, bem como das estruturas e outros equipamentos materiais urbanos ${ }^{13}$.

\footnotetext{
${ }^{13}$ Cf. Moyses, Jeferson Munhoz e Wada, Elisabeth. São Paulo Mais Hospitaleira: Projecto Cidade Limpa. Turydes - revista de investigação em turismo e desenvolvimento local. $\mathrm{N}^{\circ} 1$ outubro 2007, disponível em www.eumed.net/rev/turydes/ ou Moyses, Jeferson Munhoz e Wada, Elisabeth. São Paulo Mais Hospitaleira: Projecto Cidade Limpa [Revista Electrónica de Turismo Cultural] Número Especial - 2008. E ainda, a este propósito, repare-se na seguinte passagem: "Apesar de toda a permissividade da lei vigente anteriormente à "Lei Cidade Limpa" (Lei 15.525 de 02 de março de 2003), a sua aprovação tem levantado discussões em diversos setores da sociedade. De um lado estão grande parte dos arquitetos, urbanistas e governistas, que argumentam a favor da retirada radical da publicidade exterior a fim de "limpar" a imagem da cidade de São Paulo e expor a beleza da arquitetura e da estrutura urbana escondidas atrás dos cartazes, já que a fiscalização é ineficiente e a publicidade é considerada por alguns, danosa à saúde pública. Do lado contrário estão, principalmente, comerciantes e anunciantes, que vêem impactos
} 
As palavras de Séneca, em Da Vida Feliz, tornam-se no caso oportunas quando este afirma, rejeitando aquilo que "brilha por fora, mas por dentro é apenas miséria": "Procuremos um bem que não se afirme pela sua aparência, mas que seja sólido, constante com uma beleza interna e oculta; desenterremo-lo".

Podemos dizer que a tendência para a simulação que caracteriza a sociedade de massas é aquilo que de algum modo a Lei São Paulo, Cidade Limpa pretende contrariar. Uma certa nostalgia pelo real parece servir de inspiração a alguns dos argumentos invocados. A reposição das experiências autênticas através da elisão da artificialidade, no quadro da relação quotidiana com o espaço e paisagem urbanos, impõe-se como um objetivo contrário ao paradigma mundial da cidade do espetáculo ${ }^{14}$. A semiotização ou a disneylandização da cidade contemporânea, edificada na celebração da cultura do consumo e do ócio, não mais deverá contar com São Paulo enquanto forma espacial particularmente ilustrativa, ou expressiva nomeadamente da euforia pós-moderna, ou seja, do designado "hiper-espaço". Ao procurar regular o excesso de informação e a hiper-inflação de signos na paisagem, a Lei São Paulo, Cidade Limpa invoca assim, aparentemente, o direito à liberdade e consciência crítica individual.

Da inibição da capacidade de assimilação da informação na modernidade falava já Charles Baudelaire (O Pintor da Vida Moderna) e mais tarde Walter Benjamin (que chegou mesmo a propor a noção de "choque" para designar a súbita captação do desprevenido inconsciente), assim como Georg Simmel, entre outros.

Ao procurar apagar na sua superfície as marcas do seu próprio ambiente alucinatório, São Paulo desvincula-se, simultaneamente, da sua inscrição na rede global que outros grandes centros hiper-mediatizados articulam: Nova Iorque (Times Square), Los Angeles, Las Vegas, Tóquio, etc. Por outro lado, projetando-se, em certa medida, no modelo da cidade-histórica, aproxima-se do paradigma da cidade europeia. Nomeadamente, é sabido que a cidade de Barcelona, em particular, terá servido de fonte de inspiração à Prefeitura de São Paulo para efeitos de decisão política e elaboração da Lei. Na origem de São Paulo, Cidade Limpa terá estado o projeto Barcelona, posa't guapa, o qual se traduziu, durante um período de cerca de 10 anos,

econômicos e sociais negativos com a obrigatoriedade da retirada da publicidade do espaço público visível". Mendes, Camila Faccioni (2006) - Paisagem Urbana: uma mídia redescoberta. São Paulo: Editora SENAC.

${ }^{14}$ Sobre o referido paradigma cf. Vázquez, C. G. (2004: 78-86). 
pela retirada de outdoors em determinadas zonas da cidade, bem como pela recuperação e valorização de fachadas ${ }^{15}$.

À partida, tudo levará a crer que o projeto São Paulo, Cidade Limpa se inspira na visão culturalista da cidade, a qual conheceu o seu auge através da refundação "científica" do urbanismo com Aldo Rossi e a Tendência, por volta dos anos 60 na Europa. O que caracteriza esta visão é, antes de mais, a promoção dos valores espirituais da pessoa, em lugar das suas necessidades materiais, a promoção da identidade local e das tradições, assim como a valorização do sentido estético e artístico da cidade em detrimento da sua lógica funcional. ${ }^{16}$ Precisamente, aquilo que aqui se poderá discutir é a exclusão da publicidade exterior desse mesmo sentido estético e artístico que a fundamentação da Lei pressupõe. Segundo esta mesma Lei, um tal valor é associado, quase exclusivamente, à arquitetura bem como a determinados elementos "naturais", estruturais e topográficos, por vezes de valor histórico ou patrimonial (edifícios, praças, ruas...). Similarmente ao movimento da Tendência em Itália, a "cidade-arquitetura" ou a "cidade-disciplina" como então era designada, isto é, a conceção da cidade do estrito ponto de vista racional da construção, a par da sua acrescida valorização histórica, parece ter constituído, na verdade, um dos principais motivos de inspiração do projeto Cidade Limpa. Definindo-se a natureza publicitária, precisamente, pelo seu caráter efémero e absolutamente presenteísta, esta acaba por se constituir como uma ameaça a uma visão culturalista e histórica da cidade.

Mas os paradigmas estéticos e ideológicos subjacentes ao projeto Cidade Limpa pertencem a um tempo bem mais recuado. Já para os Gregos, "a desordem era signo de um estado de crise na sociedade" (Quessada, 2002: 174). Por seu turno, na Modernidade, a harmonia, a estabilidade, a unidade e a ordem persistiam enquanto valores indiscutíveis, os quais orientavam as práticas e políticas urbanas. Em finais do século XIX, em Paris, a Haussmannização da cidade, ou o seu "embelezamento estratégico", é disso exemplo ${ }^{17}$.

\footnotetext{
15 A propósito do referido projecto, veja-se Moyses, Jeferson Munhoz e Wada, Elisabet. São Paulo Mais Hospitaleira: Projecto Cidade Limpa [Revista Electrónica de Turismo Cultural] Número Especial - 2008: "[Projecto "Barcelona, posa't guapa"] ...uma das grandes referências em beleza urbana segundo Regina Monteiro, arquiteta e urbanista, idealizadora do Projeto Cidade Limpa de São Paulo. De porto industrial de cadente, a capital da Catalunha virou uma potência turística e uma referência em arquitetura. O processo de transformação iniciou-se em 1986 com a retirada de outdoors e a restauração de mais de 5000 fachadas, apoiada de uma forte açao de comunicação que teve a duração de 10 anos e isenção fiscal para a população em obras nas residências ou comércio".

${ }^{16}$ Cf. Vázquez, C. G. (2004: 5-14).

${ }^{17}$ Sobre as políticas urbanistas de Haussmann, diz Walter Benjamin (2002: 57.): "O ideal urbanista de Haussmann era as perspectivas sobre as quais se abriam longas fileiras de ruas. Este ideal corresponde à tendência corrente no século XIX de enobrecer as necessidades técnicas através de pseudo-fins artísticos.
} 


\section{Na recusa ou na perseguição da felicidade?}

Enfin, du point de vue du politique, la publicité représente une tentative parodique, donc ultime, de sauver le sens et la représentation comme seuls modes possibles pour concevoir l'idée d'une collectivité en acte. Même si c'est sur le mode altéré de la société de consommation de soi, la publicité propose la dernière version de la représentation, cette fiction nécessaire au commerce symbolique entre les humains afin qu'il y ait du collectif. (Quessada, 2002: 186).

O projeto São Paulo, Cidade Limpa parece querer perseguir, tardiamente, o sonho da modernidade. O bem-estar e a felicidade são entendidos à luz do pensamento platónico-cartesiano, ou seja, na recusa da desordem, do caos, do excesso ${ }^{18}$. Para Platão, a materialização da filosofia na realidade da cidade obrigava à sua submissão à ordem, em última análise a ordem universal do logos. O ideal da filosofia poderá assim julgar-se ascético, isto é, edificado na distância ao mundo e na negação dos sentidos. Como diria Sócrates, a felicidade residirá, então, não na posse de bens valiosos, mas na perda do desejo dos mesmos (Quessada, 2002: 177).

A “cidade dos sentidos", segundo o projeto Cidade Limpa, deverá cingir-se às formas arquitetónicas, o que é o mesmo que dizer, às formas indispensáveis à preservação da memória coletiva. O paradigma culturalista que outrora postulava a cidade-histórica procura assim impor-se numa tentativa de suposta restituição da "boa imagem" (Kevin Lynch, 2004) à cidade. Por "boa imagem" entende Kevin Lynch o modo como os habitantes percebem a cidade, bem como a possibilidade de construção de uma imagem mental capaz de favorecer a orientação no espaço. Precisamente, não será irrelevante notar que em resposta à invocação da questão da orientação e circulação no espaço como um dos principais argumentos que fundamentam a Lei, se tenham igualmente manifestado opiniões contrárias que referem, em resultado da extinção da publicidade exterior, a perda de valor em termos do referencial que servia essa mesma orientação.

A extinção da publicidade exterior da cidade de São Paulo significa, porém, muito mais do que uma transformação no aspeto da paisagem ou mesmo uma transformação no sentido da orientação no espaço por parte dos seus habitantes. A sua erradicação

Os tempos do poder espiritual e secular da burguesia deveria encontrar a sua apoteose no quadro das fileiras de ruas".

18 Lipovetsky e Serroy (2007: 267-272), a propósito do fenómeno da ecrãnização global, e referindo-se em particular à publicidade, reflectem criticamente sobre a "imagem-excesso" instalada na cultura contemporânea. 
compromete o espaço político concreto da cidade. Invocando Quessada (2002: 171208), podemos afirmar que a publicidade surgiu, precisamente, como a materialização dos interesses corporativistas da filosofia, o seu corpo, o seu devir-mundo. A inscrição da publicidade na polis serve, neste sentido, a ligação social junto dos passantes. Segundo Quessada (2002: 183), a filosofia, uma vez excluída da polis, terá transitado para o discurso publicitário, o qual por sua vez cumprirá uma função política pela possibilidade de confrontação de ideias a que se oferece. Afirmando-se na sua vocação retórica e persuasiva, a publicidade não deixa de se assumir, segundo a autora, como legítima herdeira da filosofia. Por meio do uso de uma linguagem simultaneamente racional e argumentativa, a publicidade não se dispensa de abrigar o Bem e a Verdade, valores outrora estritamente confinados à filosofia e em contraposição com a vida prática do quotidiano.

Como refere Qualter (1994), resiste no entanto, na nossa sociedade, uma consciência puritana. Diz o autor: "Apesar da enorme transformação cultural das últimas décadas, alguns valores puritanos ainda sobrevivem, facto que ajuda a explicar uma certa ambivalência face à publicidade" (Ibidem: 46). Na verdade, podemos equacionar a possibilidade de o debate resultante da extinção da publicidade exterior na cidade de São Paulo indiciar a resistência implícita, na contemporaneidade, de uma tensão existente entre a filosofia, na sua vocação mais idealizante, segundo a qual a felicidade é o seu próprio imperativo categórico, e a prática retórica, a arte de persuadir, herdeira da poesia e da sofística. Numa perspetiva filosófica, entende-se por felicidade a busca do sentido permanente e durável de todas as coisas. Precisamente, a publicidade confunde-se com a imagem e com o simulacro, sendo percebida como contrária a toda a referência, ou seja, como "uma insuportável impressão de presente" (Quessada, 2002: 185). É nesta medida que a fundamentação discursiva do projeto Cidade Limpa defende a necessidade de aniquilação das imagens e a simultânea reposição do referencial arquitetónico ou natural. Em lugar do simulacro, defende-se a suposta presença inteira da coisa mesma.

Porém, convém não esquecer que propondo a substituição do mundo por uma sua representação ideal, a publicidade partilha, paradoxalmente, o propósito da própria filosofia, isto é, "apresenta-se como o discurso providencial que, em si mesmo, pode conduzir os humanos, integrados em sociedade, no sentido da felicidade individual e coletiva..." (Quessada, 2002: 185). Segundo Quessada (Idem: 191-192):

A publicidade representa o modo como a filosofia se pôde realizar no mundo através de uma vitória dos ideais democráticos. Ela dá forma, realidade e 
atualidade à ideia filosófica de uma comunidade regida racionalmente por um discurso ao qual os cidadãos aderem «livremente», isto é, através de uma servidão total e voluntária à ordem uniformizante do logos racional.

No quadro da sociedade pós-moderna, a felicidade corresponde, frequentemente, e tal como aponta Lipovetsky (2006), a um sentimento paradoxal. Por um lado, o bem-estar material é-nos prometido como porta de acesso a uma desejada vida feliz. Por outro, uma vez submetidos à ordem universal do consumo, os indivíduos tornam-se ao mesmo tempo cativos da ansiedade, medo e insegurança que essa mesma ordem estimula.

A par da questão ética, coloca-se a questão estética da publicidade. Tomando como ponto de partida o enunciado de Jean Baudrillard segundo o qual a publicidade em si mesma é o produto que, antes de mais, consumimos, podemo-nos interrogar sobre a importância da experiência estética do consumo como ingrediente da própria "felicidade". Concebida, em particular, para o consumo do olhar, a publicidade exterior oferece-se à possibilidade do simples prazer de um efémero passeio imaginário. Numa cidade como São Paulo, embora esta seja suscetível de se propiciar a um certo culto da indiferença à imagem, a prática quotidiana de circulação, com todas as contrariedades inerentes implicadas (filas de trânsito...), não deixa de se abrir, pontualmente, ao desejo de repouso e distração do olhar...

\section{Desejo de ordem vs experiência do caos}

A publicidade partilha com a filosofia platónico-cartesiana de um determinado desejo de "ordem uniformizante". Porém, o projeto Cidade Limpa pressupõe que a publicidade exterior reproduz a organicidade desregrada de uma espécie de "corposem-órgãos" (Deleuze e Guattari), isto é, a mistura de formas e de funções em que se traduz o temido caos urbano. Esvaziada de conteúdo, a publicidade esvazia-se da sua própria função discursiva, uma vez percebida na sua estrita natureza formal e, como tal, enquanto parte indiferenciada de um tecido fractal que urge combater ${ }^{19}$. O que por sua vez se torna igualmente contraditório, atendendo a que se admite, no quadro da própria teoria do caos, a existência de uma ordem. Diversos urbanistas contemporâneos referem que a entropia ou a aparência caótica das grandes metrópoles, nomeadamente no que diz respeito a algumas das cidades norte-americanas, caracteriza a condição evanescente do chamado tardo-capitalismo.

\footnotetext{
${ }^{19}$ Sobre o «fractal» (definido como forma geométrica simples que se repete em níveis cada vez mais pequenos, indiciando a existência de uma forma comum unificadora da natureza), aplicado a uma visão organicista da cidade, pronuncia-se Vásquez (2004: 123-126).
} 
Sobretudo, importará considerar o carácter de permanente mobilidade que inviabiliza qualquer sonho de fixação ou permanência da noção ontológica de cidade. O espaço urbano é, talvez, cada vez mais liquefeito e a sua materialidade possível encontra na permanente fluidez um modo rizomático de se fazer corpo. Neste sentido, a publicidade exterior serve apenas uma imparável transformação que por via da relação, tantas vezes tensiva, entre o individual e o social, se agiliza. Em si, a publicidade exterior não é um bem nem é um mal. Apenas participa da enfermidade, mais ou menos visível, da cidade-vivida...

\section{Referências Bibliográficas}

Aristóteles (2004) Ética Nicomaquea / Política, México: Porrúa.

Aristóteles, Epicuro, Marco Aurelio, Cicerón, Séneca \& Plutarco (2001) La Felicidad, México: Alamah.

Baudelaire, C. (2013) O Pintor da Vida Moderna, Editora Nova Vega.

Baudrillard, J. (1986) Amérique, Paris: Grasset.

Benjamin, W. [Tiedmann, Rolf (Ed.)] (2002) Arcades Project, Belknap Press.

Bentham, J. (2007) [1780] An Introduction to the Principles of Morals and Legislation, NY : Dover Publications.

Bruckner, P. (2002) A Euforia Perpétua. Ensaio Sobre o Dever de Felicidade, Lisboa: Notícias Editorial (trad. António Cruz Belo).

Debord, G. (1992) La Société du Spectacle, Paris: Gallimard.

Deleuze, G. \& Guattari, F. (S/D) O Anti-Édipo. Capitalismo e Esquizofrenia, Lisboa: Assírio \& Alvim.

Epicuro \& Séneca (2008) Carta Sobre a Felicidade [Epicuro] e Da Vida Feliz [Séneca], Lisboa: Relógio D'Água (trad. João Forte).

García Vázquez, C. (2004) Ciudad hojaldre. Visiones urbanas del siglo XXI, Barcelona: Gustavo Gili (78-86).

Lipovetsky, G. (2007) A Felicidade Paradoxal. Ensaio Sobre a Sociedade do Hiperconsumo, Lisboa: Edições 70 (trad. Patrícia Xavier).

Lipovetsky, G. \& Serroy, J. (2007) L'Écran Global, Paris: Seuil.

Lynch, K. (2004) La Imagem de la Ciudad, Barcelona: Gustavo Gili.

Maffesoli, M. (1979) La Conquete du Présent, Paris: PUF. 
Piqueira, G. (2007) São Paulo, Cidade Limpa, São Paulo: Rex Projetos e Editora.

Quessada, D. (2002) L'esclavemaître, Paris: Éditions Verticales.

Qualter, T. H. (1994) Publicidad y Democracia en La Sociedad de Masas, Barcelona: Ediciones Paidós.

Simmel, G. (2011) Philosophy of Money, Taylor and Francis.

Smith, A. (2005) [1776] An Inquiry into the Nature and Causes of the Wealth of Nations, Pennsylvania State University.

Walter B. (2002) Paris, Capitale du XIXe Siècle. Le Livre des Passages, Paris: Cerf.

Weber, M. (2001) A Ética Protestante e o Espírito do Capitalismo, Lisboa: Editorial Presença.

Helena Pires é Professora Auxiliar no Departamento de Ciências da Comunicação da Universidade do Minho e investigadora do CECS (Centro de Estudos de Comunicação e Sociedade), Universidade do Minho.

hlena.pires538@gmail.com; hpires@ics.uminho.pt 